\title{
La infiltración policial en España como medio de investigación en la lucha contra la corrupción
}

\author{
Police infiltration in Spain as an investigative \\ measure for fighting corruption
}

\section{Adán Carrizo González-Castell}

Profesor Contratado Doctor de Universidad de Salamanca/ESP adancgc@usal.es orcid.org/0000-0002-6134-8874

RESUMEN: El presente artículo aborda la figura de la infiltración policial y la necesidad de su utilización en la lucha contra la corrupción y el crimen organizado analizando no solo la normativa española sino también la contenida en los instrumentos internacionales vigentes en la Unión Europea, destacando la importancia de la cooperación internacional en este ámbito.

Palabras Clave: Infiltración policial; agente encubierto; diligencias de investigación; cooperación penal internacional.

ABSTRACT: The present paper addresses the concept of police infiltration, as well as the necessity of its use for fighting corruption and organized crime. In doing so, we analyze not only Spanish law, but also existing international legislation in the European Union, with particular emphasis on international cooperation in this field.

KEYWORDs: Police infiltration; undercover agent; investigation diligences; international criminal cooperation.

SUMARIO: Introducción; 1. La infiltración policial como técnica de investigación en la lucha contra la corrupción; 2 . La infiltración policial en España; 2.1. Concepto y normativa reguladora; 2.2. Ámbito de aplicación; 2.3. Requisitos para la utilización de la figura del agente encubierto; 2.4. Identidad supuesta y protección del agente encubierto; 2.5. Responsabilidad del agente encubierto; 3 . Infiltración policial y recuperación de activos; Consideraciones finales; Bibliografía. 


\section{INTRODUCCIÓN}

Desgraciadamente para los ciudadanos de ambos países, tanto Brasil como España comparten una preocupación importante en relación con la lucha contra la corrupción, como demuestra el enorme interés despertado por la operación Lava Jato, considerada como la mayor investigación de corrupción en la historia de Brasil, o que, una vez más, y según los datos del último barómetro del Centro de Investigaciones Sociológicas de España, que hemos conocido en la fecha de cierre de este trabajo, la corrupción y el fraude, vuelvan a situarse como uno de los principales problemas para los españoles, ocupando el segundo lugar, tan solo superado por el desempleo ${ }^{1}$.

Esta corrupción, cada vez más desarrollada y, en muchos casos de carácter transnacional, hace que el recurso a la técnica del agente infiltrado, pese a tratarse de una medida claramente restrictiva de derechos fundamentales, se encuentre regulada en multitud de instrumentos normativos de carácter internacional y haya terminado siendo algo naturalmente admitido por la práctica totalidad de los ordenamientos jurídicos en la lucha contra este tipo de delitos.

Habida cuenta de la remisión a la normativa nacional que realizan los instrumentos internacionales sobre la materia, pretendemos a lo largo del presente trabajo realizar un estudio de la legislación española que nos permita llegar a una serie de conclusiones críticas sobre la idoneidad de esta figura para luchar contra la corrupción y el crimen organizado, y sobre si la utilización de la misma resulta o no compatible con los derechos fundamentales y con los principios y garantías que inspiran nuestro sistema procesal.

\section{LA INFILTRACIÓN POLICIAL COMO TÉCNICA DE INVESTIGACIÓN EN LA LUCHA CONTRA LA CORRUPCIÓN}

Como hemos tenido ocasión de señalar, el carácter cada vez más complejo y generalmente transnacional de la corrupción ha hecho que el re-

1 Barómetro de octubre de 2016. Estudio número 3156 del Centro de Investigaciones Sociológicas disponible en http://www.cis.es/cis/export/sites/default/-Archivos/Marginales/3160_3179/3168/es3168mar.pdf Fecha de última consulta: 7 de abril de 2017. 
curso a la infiltración policial aparezca regulado en multitud de instrumentos normativos de carácter internacional, concretamente lo encontramos, bajo el nombre de operaciones encubiertas, entre las técnicas especiales de investigación previstas en el artículo 50 de la Convención de las Naciones Unidas contra la Corrupción, también llamada Convención de Mérida así como en el artículo 20 de la Convención de las Naciones Unidas contra la Delincuencia Organizada Internacional o Convención de Palermo².

Sin embargo, esta previsión internacional, no la encontramos solo en las Convenciones mencionadas, adoptadas en el ámbito de las Naciones Unidas, sino que en cumplimiento precisamente de lo que las mismas señalan, al alentar a los Estados Parte a que celebren, cuando proceda, acuerdos bilaterales o multilaterales apropiados para utilizar esas técnicas en el contexto de la cooperación en el plano internacional, debemos destacar que dicha figura ha sido igualmente prevista en otros instrumentos internacionales de carácter regional, como los firmados en el marco de la Unión Europea o del Consejo de Europa.

En este sentido, el artículo 14 del Convenio de Asistencia Judicial en materia penal entre los Estados miembros de la Unión Europea, de 29 de mayo de 2000, que tiene como finalidad complementar el firmado en el marco del Convenio de Europa en 1959, define lo que ha de entenderse por investigación encubierta al señalar que el Estado miembro requirente y el Estado miembro requerido podrán convenir en colaborar para la realización de investigaciones de actividades delictivas por parte de agentes que actúen infiltrados o con una identidad falsa ${ }^{3}$.

2 Ambas Convenciones, tanto la de Palermo como la de Mérida, insisten en la penalización de la corrupción entendiendo como tal la promesa, el ofrecimiento o la concesión hecha a un funcionario público (o la solicitud o aceptación por parte del mismo) directa o indirectamente, de un beneficio indebido que redunde en su propio provecho o en el de otra persona o entidad, con el fin de que dicho funcionario actúe o se abstenga de actuar en el cumplimiento de sus funciones oficiales. En este sentido se insta a los diferentes Estados a que adopten, en la medida en que proceda y sea compatible con su ordenamiento jurídico, medidas eficaces de carácter legislativo, administrativo o de otra índole para promover la integridad y para prevenir, detectar y castigar la corrupción de los funcionarios públicos.

3 Convenio de asistencia judicial en materia penal entre Estados miembros de la Unión Europea (establecido mediante Acto del Consejo de 29 de mayo del 2000, DOCE C 197 de 12.07.2000). 
Una regulación similar, a salvo de las diferencias que a continuación trataremos, la encontramos en el artículo 29 de la Directiva 2014/41/CE del Parlamento Europeo y del Consejo, de 3 de abril de 2014, relativa a la orden europea de investigación en materia penal, que debería ser transpuesta, conforme a lo señalado en el artículo 36 de la misma, antes del 22 de mayo de 2017, fecha en la que deberá sustituir a la regulación prevista en el Convenio de Asistencia Judicial en materia penal del año 2000 al que hemos hecho referencia ${ }^{4}$.

Esta orden europea de investigación nace como fruto de la necesidad detectada de crear una especie de derecho probatorio en el marco de la Unión Europea que facilite la obtención de pruebas en casos de delitos de carácter supranacional, principalmente de dimensión transfronteriza como los que nos ocupan ${ }^{5}$.

En relación con las investigaciones encubiertas, el artículo 29 de la Directiva 2014/41/CE señala que podrá emitirse una orden europea de investigación con el fin de solicitar al Estado de ejecución que colabore con el Estado de emisión para la realización de investigaciones de actividades delictivas por parte de agentes que actúen infiltrados o con una identidad falsa. Esta nueva regulación, aunque muy similar a la anterior, supera ampliamente a la del Convenio del año 2000 al hablar de Estado de emisión y de Estado de ejecución, obviando la referencia

4 Sobre el contenido de esta Directiva puede consultarse, entre otros, MARTINEZ GARCÍA, E., (2016) La orden europea de investigación, Editorial Tirant lo Blanch, Valencia y DIAZ PITA, M. P., (2015) “La orden europea de investigación en materia penal (OEI) y la lucha contra la criminalidad organizada transnacional en la Unión Europea”, Observatorio de Criminalidad Organizada Transnacional, Mayo de 2015, disponible en http://crimtrans. usal.es/?q=node/138.

5 Esta aspiración ya había sido recogida en el Libro Verde sobre la obtención de pruebas en materia penal en otro Estado miembro y sobre la garantía de su admisibilidad, publicado por la Comisión el 11 de noviembre de 2009 y se reproduce igualmente en el Programa de Estocolmo de 11 de diciembre de 2009 relativo a un espacio de libertad, seguridad y justicia al servicio de los ciudadanos, que proponía sustituir los instrumentos existentes por un régimen general de obtención de elementos de pruebas que cubriera, en la medida de lo posible, todos los tipos de medidas de investigación, y al que denomina "mandato europeo de obtención de pruebas" germen de lo que luego sería la orden europea de investigación. Sobre la situación actual en este ámbito puede verse MARTIN GARCÍA, A. L. y BUJOSA VADELL, L.M., (2016). 
clásica al Estado requirente y Estado requerido propia de los tratados y de los convenios internacionales.

Y es que la orden europea de investigación nace como un instrumento más dentro del espacio de libertad, seguridad y justicia de la Unión Europea, fundamentado sobre la base del principio de reconocimiento mutuo de resoluciones; principio que ha dado lugar a la aprobación en España de la Ley 23/2014, de 20 de noviembre, de reconocimiento mutuo de resoluciones penales en la Unión Europea, que lamentablemente quedará en breve obsoleta al no recoger aún este nuevo instrumento de reconocimiento mutuo y que deberá ser necesariamente modificada para incluirlo ${ }^{6}$.

Establece también la Directiva que estamos analizando que, en cada caso particular, la decisión relativa al reconocimiento y ejecución de una orden europea de investigación será adoptada por las autoridades competentes del Estado de ejecución ateniéndose a su Derecho interno y a sus procedimientos nacionales, lo que supone una clara remisión a la legislación de dicho Estado en cuanto a la autoridad competente para autorizar dicha medida y sobre la forma en la que se realizará la investigación encubierta, señalándose que se realizarán de conformidad con el Derecho y los procedimientos del Estado miembro en cuyo territorio se realicen.

Sin embargo, y pese a estar generalmente admitida por la mayoría de los Estados de nuestro entorno y ser reconocida en un instrumento normativo de carácter vinculante para los Estados miembros de la Unión Europea como es la mencionada Directiva, lo cierto es que no encontramos un concepto unitario que nos sirva para definir que podemos entender por agente infiltrado, siendo múltiples, diversas y variadas las regulaciones que sobre esta figura existen ${ }^{7}$.

6 BOE de 21 de noviembre de 2014. Para una aproximación teórico-práctica a esta ley puede consultarse VV.AA., Reconocimiento mutuo de resoluciones penales en la Unión Europea, (ARANGÜENA FANEGO, C., DE HOYOS SANCHO, M., RODRÍGUEZ-MEDEL NIETO, C., coordinadoras), (2015).

7 Para un análisis más detallado de estas diferentes regulaciones que van desde las que se realizan con cierta amplitud hasta aquellos supuestos en los que no existiendo norma legal la infiltración policial ha sido admitida por la Jurisprudencia pueden verse los trabajos de GASCÓN INCHAUSTI, F., (2001) y de DELGADO GARCÍA, M. D., (1996). 


\section{LA INFILTRACIÓN POLICIAL EN España}

\subsection{CONCEPTO Y NORMATIVA REGULADORA}

Como primera aproximación a esta figura, diremos que la característica fundamental de la infiltración consiste en la ocultación de la verdadera identidad del sujeto, que adopta una nueva identidad ficticia con el objetivo fundamental de establecer una relación de confianza e intimidad con los presuntos delincuentes que le permita obtener información que sirva para la persecución penal de los mismos 8 .

La regulación legal del agente infiltrado la encontramos en el artículo 282 bis de la Ley de Enjuiciamiento Criminal española de 1882, recientemente modificado para incorporar la figura del agente encubierto a través de internet, y que supone una muestra más de la necesaria sustitución de la misma por una Ley o Código más moderno y actualizado que responda a los nuevos retos de una sociedad cada vez más compleja y avanzada? .

La redacción original de dicho artículo fue llevada a cabo por la Ley Orgánica 5/1999 de 13 de enero, de modificación de la Ley de Enjuiciamiento Criminal en materia de perfeccionamiento de la acción investigadora relacionada con el tráfico ilegal de drogas y otras actividades ilícitas graves, cuya Exposición de Motivos señalaba que las reformas que se incorporaban respondían a la insuficiencia de las técnicas de investigación tradicionales en la lucha contra el crimen organizado.

8 Se trata como afirma GOMEZ DE LIAÑO FONSECA-HERRERO, M., (2004) de una figura de grandes complejidades no sólo técnicas, sino también prácticas, de la que resulta conveniente acotar sus líneas características para diferenciarla de otras figuras afines. Sobre la figura del agente encubierto en España pueden consultarse, entre otros, los trabajos de ALONSO PÉREZ, F., (2002); CARMONA SALGADO, C., (2003); DELGADO MARTÍN, J., (2000); DELGADO MARTÍN, J., (2001); GASCÓN INCHAUSTI, F., (2001); RIFÁ SOLER, J. M., (1999) y más recientemente VV.AA. (2016) Conclusiones de las Jornadas sobre el Marco Jurídico de Actuación del Agente Encubierto así como Para una aproximación a esta regulación en legislación brasileña puede consultarse CARDOSO PEREIRA, F., (2016) quien realiza un magnífico análisis desde el punto de vista del garantismo procesal.

9 Sobre el agente encubierto a través de Internet puede consultarse BUENO DE MATA, F. (2012); LAFONT NICUESA, L. (2015) o VALIÑO CES, A. (2016). 
De esta forma, se reconocía de forma expresa la necesidad de introducir en el ordenamiento jurídico medidas legales especiales que permitieran a los miembros de la Policía Judicial participar del entramado organizativo, detectar la comisión de delitos e informar sobre sus actividades, con el fin de obtener pruebas incriminatorias y proceder a la detención de los autores, respetando el fin del proceso penal que no es otro que el descubrimiento de la verdad real y la aplicación de la ley penal al caso concreto y teniendo siempre en cuenta que los límites de las técnicas propuestas de investigación se encuentran en el sistema de derechos y garantías que la Constitución reconoce a todo investigado, ya que por más terribles que sean las formas de delincuencia que se tratan de combatir, ello no justificaría la utilización de medios investigadores que puedan violentar garantías constitucionales.

Lo cierto es que, al margen de estas razones, la regulación de esta figura también daba solución a la obligación impuesta por el artículo 14 del Convenio de Asistencia Judicial en materia penal entre los Estados miembros de la Unión Europea, al que ya hemos hecho referencia que, por su remisión al derecho interno, hacía conveniente establecer las autoridades competentes para tomar la decisión sobre si procede o no autorizar dicha forma de asistencia acordando, en todo caso, la duración de la investigación encubierta, las condiciones concretas, el régimen jurídico de los agentes de que se trate o los supuestos delictivos respecto de los cuales puede solicitarse una investigación encubierta ${ }^{10}$.

Volviendo al análisis de la regulación nacional, y dejando para más tarde el ámbito de aplicación y la autoridad competente para autorizar el recurso a esta figura, que analizaremos en los siguientes apartados, debemos señalar que, en lo que se refiere al sujeto activo de la infiltración, es decir: a la determinación de quién puede ser autorizado para actuar como agente encubierto en España, esta posición solo puede ser ocupada por un funcionario de policía, con las consideraciones que seguidamente expondremos, a diferencia de otros países en los que estaría permitida la autorización de un tercero.

10 En este sentido se pronuncia el Informe explicativo 2000/C 379/02 del Convenio, de 29 de mayo de 2000, relativo a la asistencia judicial en materia penal entre los Estados miembros de la Unión Europea, aprobado por el Consejo el 30 de noviembre de 2000, DOCE C 379 de 29.12.2000. 
En este sentido, en España, solo podrá ser agente encubierto conforme al artículo 282 bis de la Ley de Enjuiciamiento Criminal un miembro de la Policía Judicial; si bien en este aspecto se plantea un problema derivado de la antigüedad de la ley procesal española, que data de finales del siglo XIX y en la que se entiende por Policía Judicial a un elenco demasiado grande de personas y grupos. Este motivo hace que nos parezca más acertado optar por la definición contenida en el artículo 1 del Real Decreto 769/1987, de 19 de junio sobre regulación de la Policía Judicial, que dispone que las funciones generales de Policía Judicial corresponden a todos los miembros de las Fuerzas y Cuerpos de Seguridad, antes que por la contenida en el artículo 283 de la Ley de Enjuiciamiento Criminal, que debería ser fruto de una profunda reforma, ya que conforme a una interpretación literal de la misma, cualquiera de los contenidos en dicho precepto podría actuar como agente encubierto. Este hecho, aparte del evidente riesgo adicional que puede conllevar la actuación como agente infiltrado pensamos que es la razón por la que la legislación establece la imposibilidad de que una persona pueda ser obligada a actuar como agente infiltrado ${ }^{11}$.

Evidentemente, y en consonancia con la crítica hecha a la regulación española que por antigua y obsoleta podría permitir que alguna persona que no esté lo suficientemente preparada actuara como agente infiltrado, no nos parecería aceptable, conforme a lo señalado anteriormente, que terceros no vinculado con ningún cuerpo policial, puedan desarrollar esta actividad, mucho menos cuando las personas utilizadas para este fin pueden ser incluso otros delincuentes o personas que tengan algún tipo de deuda con la justicia.

En este sentido compartimos la opinión de aquellos autores que insisten en la necesidad de que la persona que desarrolle estas funciones sea un profesional lo suficientemente preparado y que reúna una serie de cualidades excepcionales tanto en el plano operativo como

11 Así deberán actuar como agentes encubiertos aquellos que voluntariamente quieran prestar dichos servicios y que, a su vez, reúnan una serie de cualidades, tales como una formación adecuada, con conocimientos jurídicos, técnicos o psicológicos, que permita velar por los aspectos de seguridad del agente. A dicha Conclusión se llegó durante el Seminario Internacional sobre Agentes Encubiertos organizado por el Consejo General del Poder Judicial en octubre de 1999. 
en el plano ético, ya que si la ética de la utilización de este medio de investigación puede estar en algún momento en entredicho lo estará mucho más si quienes actúan como agente infiltrado proceden del mundo de la delincuencia y del crimen ${ }^{12}$.

\section{2. ÁMBITO DE APLICACIÓN}

En el artículo 282 bis de la Ley de Enjuiciamiento Criminal española, aparte de proporcionarse habilitación legal a la figura del agente encubierto en el marco de una investigación, posibilitándose el otorgamiento y la utilización de una identidad supuesta a funcionarios de la Policía Judicial, se delimita el concepto de delincuencia organizada, la única para cuya investigación se prevé la infiltración policial, y se determinan, en el apartado 4 del mismo, las figuras delictivas en las que podrá utilizarse esta técnica en el marco de la misma ${ }^{13}$.

En este sentido, y para centrar el ámbito de aplicación de esta figura, debemos señalar que, conforme a la regulación española se considerará como delincuencia organizada la asociación de tres o más personas para realizar, de forma permanente o reiterada, conductas que tengan como fin cometer alguno o algunos de los delitos mencionados en dicho artículo, lo que supone una restricción importante del ámbito

12 En este sentido GUEDES VALENTE, M. M., (2008) quien señala que si el agente infiltrado es una técnica excepcional, no tiene sentido que el legislador deje abierta la posibilidad de que la Policía Judicial pueda infiltrar un tercero sin que tenga limitada la cualidad de ese tercero, debiendo, por ejemplo, prohibir que sean infiltrados individuos que estén cumpliendo pena de prisión, o que estén bajo investigación criminal y como atenuante de la pena.

13 Sobre el listado de delitos en España se muestran críticos RIFÁ SOLER, J. M., (2001) quien considera que esta técnica se concilia muy mal con la constante evolución del crimen organizado y DARIO CERINA, G., (2008) quien, aunque aprecia el hecho de que la técnica utilizada no deja dudas del ámbito de aplicación del agente encubierto, entiende sin embargo que se trata de una solución cercana a la que adoptaban los Códigos decimonónicos. Tampoco, desde nuestro punto de vista, debería valernos el criterio de la cuantía de la pena para determinar la gravedad o no de la criminalidad organizada ya que como señala el Tribunal Europeo de Derechos Humanos, en su STEDH Malone c. Reino Unido, de 2 de agosto de 1984, "ligar el crimen organizado a la entidad cuantitativa de la infracción supone observar el fenómeno con límites muy estrechos”. 
de utilización de esta figura ya que cuando el tipo penal sea cometido solo por una o dos personas no podría recurrirse a esta técnica.

Esta limitación nos parece acertada, por cuanto, normalmente, son los delitos cometidos en el seno de una organización criminal los que suelen plantear mayor complejidad y los que requieren el recurso a medidas de investigación tan restrictivas de derechos fundamentales como el agente infiltrado, debiendo recurrirse a esta figura solo cuando sea absolutamente necesario ${ }^{14}$.

Del mismo modo nos parece correcto que, a diferencia de lo que sucede en otras legislaciones de nuestro entorno, como la portuguesa, por ejemplo, la infiltración policial en España solo pueda ser utilizada para la investigación de delitos ya cometidos y, en ningún caso, con fines preventivos ya que consideramos que en estos supuestos no se dan las características de excepcionalidad, necesidad y subsidiariedad exigidas debiendo buscarse otros medios mucho menos restrictivos de derechos fundamentales ${ }^{15}$.

\subsection{REQUISITOS PARA LA UTILIZACIÓN DE LA FIGURA DEL AGENTE ENCUBIERTO}

Si partimos de la base, como efectivamente lo hacemos, de que la utilización del agente encubierto es un medio excepcional de investigación restrictivo de derechos fundamentales, debemos también partir de la base de que ésta debe cumplir los requisitos exigidos por la jurisprudencia Constitucional a la hora de permitir estas medidas, es decir debe someterse a los requisitos de necesidad, idoneidad, adecuación y, por supuesto,

14 Compartimos la opinión de GUEDES VALENTE, M. M., (2008) al señalar que como técnica excepcional, el agente infiltrado, ya sea por razones de orden moral o ético, ya sea por razones de seguridad del propio agente infiltrado, solamente debe ser usada cuando todos los demás medios de obtención de prueba no fueran suficientemente capaces y eficaces para la averiguación de la verdad. Existen autores que van más allá criticando su utilización incluso en la investigación de delitos como SEQUEROS SAZATORNIL, F., (2000) cuando indica que "es contrario a la dignidad de la persona que se utilicen precisamente las buenas cualidades que puedan restarle a un presunto delincuente, como pudieran ser la apertura al otro, el culto a la amistad, la solidaridad o, tal vez, el deseo de ayudar, como medios para el descubrimiento del delito".

15 Sobre la función preventiva y represiva que permite la Ley 101/2001 de 25 de agosto portuguesa se pronuncia de manera crítica COSTA ANDRADE, M., (1992). 
autorización judicial que deberá contener una contundente justificación y motivación en la que se demuestre la idoneidad de la medida y que ésta responde a una necesidad dentro de los fines de la investigación ${ }^{16}$.

En este sentido el artículo 282 bis de la Ley de Enjuiciamiento Criminal española nos indica, y a la vez nos plantea nuevos interrogantes, cuál debe ser la autoridad competente para autorizar el recurso al agente infiltrado, al señalar que, cuando se trate de investigaciones que afecten a actividades propias de la delincuencia organizada, la facultad para autorizar una investigación encubierta corresponde al Juez de Instrucción competente, o al Ministerio Fiscal dando cuenta inmediata al Juez.

Dicha regulación nos parece absolutamente desafortunada en el sentido de que, como hemos anticipado, al tratarse de una medida restrictiva de derechos fundamentales no podemos admitir ni tolerar que dicha medida pueda ser autorizada por el Ministerio Fiscal, ni siquiera dando cuenta de forma inmediata al Juez de Instrucción, motivo por el cual entendemos que la autoridad competente para autorizar la actuación de un agente infiltrado deberá ser el Juez al que le corresponda la instrucción del caso que aconseje la realización de una investigación encubierta, convirtiéndose precisamente la posibilidad de que lo haga el Ministerio Fiscal en uno de los aspectos más espinosos de la regulación de esta figura, es decir, en los límites de la competencia que la propia Ley de Enjuiciamiento Criminal española atribuye al Ministerio Fiscal para que autorice por si mismo la adopción de la medida, ya que para algunos autores esta atribución de competencia se apartaría de lo que podríamos denominar un efectivo control judicial, proponiendo una interpretación más acorde con dicho control y que consideramos mucho más acertada, según la cual la competencia del Fiscal se limitaría a proponer la adopción de esta medida, pero no a adoptarla directamente por sí mismo ${ }^{17}$.

16 Como ejemplos pueden mencionarse la Sentencia del Tribunal Constitucional español núm. 207/1996, que indica que la medida debe ser idónea (apta, adecuada) para alcanzar el fin constitucionalmente legítimo perseguido con ella sirviendo objetivamente para determinar los hechos que constituyen el objeto del proceso penal, así como la STC 116/1998, de 2 de junio, en relación con la necesaria motivación de la medida.

17 Se muestra de esta opinión RIFÁ SOLER, J. M., (1999) para quien el Fiscal debería elevar esta solicitud al Juez competente para que este decida sobre si corresponde abrir diligencias previas o sumario o denegar la medida, 
Consideramos que el legislador español no fue consciente de que la mera autorización para la intervención de un agente encubierto ya supone una diligencia sumarial restrictiva de derechos fundamentales, motivo por el cual debemos mostrarnos especialmente críticos con que la autorización de esta figura pudiera corresponder en algún caso al Ministerio Fiscal, puesto que la ocultación de la condición del agente determina por sí sola una restricción del derecho a la intimidad de los miembros de la organización investigada ya que, de otra manera el agente no habría tenido acceso a datos, situaciones y confidencias que desde nuestro punto de vista forman parte del derecho a la intimidad de las personas, entendido en un sentido amplio como el poder de control sobre las informaciones que son relevantes para cada sujeto ${ }^{18}$.

Sin embargo, el hecho de que el recurso a la figura del agente encubierto pueda suponer una intromisión en el derecho fundamental a la intimidad no nos puede servir para desechar el uso de la misma por cuanto el derecho a la intimidad no es un derecho absoluto sino que se encuentra delimitado por los restantes derechos fundamentales y bienes jurídicamente protegidos, pudiendo ser objeto de intromisiones legítimas siempre que se den los presupuestos oportunos, entre los cuales se encuentra, no solo la proporcionalidad de la medida sino también y por supuesto la autorización judicial ${ }^{19}$.

señalando además que el único receptor de los resultados obtenidos por el agente será el órgano judicial autorizante. En el mismo sentido se pronuncian GUARIGLIA, F. (1994) quien aclara las diferentes funciones atribuidas al Juez de Instrucción y al Ministerio Fiscal en otras regulaciones de nuestro entorno y GASCON INCHAUSTI. F. (2001) quien considera que pese a esta regulación, en la práctica será imprescindible desde el principio contar con la preceptiva autorización judicial, por la necesidad de permitir al infiltrado la entrada en domicilios privados, sin la cual su labor sería papel mojado.

En este sentido compartimos las opiniones de DELGADO MARTÍN, J., (2001) y GASCÓN INCHAUSTI, F., (2001); MORENILLA RODRÍGUEZ, J. M., (1993) y LOPEZ ORTEGA, J. J., (1996) a pesar de que existan sentencias del Tribunal Europeo de Derechos Humanos, como la de 15 de junio de 1992 (caso Ludí) que consideran que el recurso a un agente encubierto no afecta por si, ni en combinación con las escuchas telefónicas, a la esfera privada de los investigados puesto que desde el momento en que estos están cometiendo un hecho delictivo deben saber que corren el riesgo de encontrar a un funcionario de policía infiltrado encargado de desenmascararlo.

19 Sobre la posible quiebra del monopolio judicial puede verse DARIO CERINA, G., (2008) cuya opinión no compartimos para el caso de la utilización del 
Aclarado por tanto que la autoridad que puede autorizar el recurso al agente infiltrado debería ser única y exclusivamente sólo la autoridad judicial nos detendremos ahora en los requisitos que debe contener dicha autorización que, para empezar, deberá revestir la forma de auto y contener, no solo el juicio de proporcionalidad sobre la necesidad de la medida al que antes hemos hecho referencia, es decir, la motivación de que resulta estrictamente necesaria para la finalidad de la investigación, ya que de otra forma no sería aceptable en el marco del respeto del debido proceso; sino también los hechos que justifican la concurrencia de las circunstancias que aconsejan su adopción, tales como la existencia de indicios racionales de la comisión, en forma organizada, de alguno de los delitos a los que se refiere el artículo 282 bis 4 de la Ley de Enjuiciamiento Criminal y que no exista ninguna otra vía menos restrictiva de derechos para conseguir el esclarecimiento de los hechos, es decir que se garantice su carácter subsidiario con respecto a las demás técnicas de investigación de delitos ${ }^{20}$.

Está resolución también deberá contener, desde nuestro punto de vista, los delitos cuya comisión se sospecha y que pueden ser objeto de investigación entre los que destacaríamos, en la línea ya anticipada durante todo este trabajo, aquellos relacionados con la corrupción pues esta resulta especialmente dolorosa para el Estado de Derecho, en la medida de que, cuando existe corrupción, a pesar de tratarse de un fenómeno opaco y difícil de cuantificar, se considera que se está privando

agente encubierto al considerar que aunque el Tribunal Constitucional español, en STC de 24 de marzo de 2003, entre otras, haya podido admitir en materia de derecho a la intimidad, que de forma excepcional, en determinados casos y con la suficiente y precisa habilitación legal sea posible que la policía judicial realice determinadas prácticas que constituyan una injerencia leve en la intimidad de las personas, este no es el caso del agente encubierto donde la injerencia no puede calibrarse en ningún caso de leve y donde el Estado está acudiendo al engaño para producir esa injerencia.

20 De esta opinión se muestran DELGADO MARTÍN, J., (2000); GASCÓN INCHAUSTI, F., (2001), GUARIGLIA, F., (1994) y GUEDES VALENTE, M. M.,(2008) para quien solo se recurrirá a este medio o técnica excepcional de investigación cuando el resto de medios o técnicas menos gravosas para el ciudadano se demuestren inadecuadas o incapaces de producir prueba real y personal o cuando la complejidad o la alta y especialísima gravedad del crimen, como en el caso de la criminalidad organizada, hagan imposible obtener las pruebas de otra manera. 
a ese Estado de un correcto desarrollo efectivo, por cuanto en muchas ocasiones las decisiones políticas son adulteradas por los intereses privados de unos pocos que, mediante sobornos, bloquean las oportunidades de desarrollo que deberían tener las personas ${ }^{21}$.

Del mismo modo dicha autorización deberá contener el nombre del investigado o investigados que son objeto de la investigación y las actividades que el agente está facultado para realizar y que consistirán, como norma general, en actuar bajo identidad supuesta, adquirir y transportar los objetos, efectos e instrumentos del delito y diferir la incautación de los mismos, ya que debemos tener en cuenta que cualquier actuación que quebrante las garantías fundamentales, no podrá ser utilizada en el proceso penal, pudiendo incluso generar responsabilidades, disciplinarias o penales para el agente, lo que nos lleva a la conclusión de que la intervención de agentes encubiertos debe estar circunscrita y rodeada de una serie de garantías que aseguren que no sacrifiquemos las mismas por conveniencia ${ }^{22}$.

Otra disposición, referente al control judicial de la actividad del agente encubierto, vendría determinada por el apartado 3 del artículo 282 bis de la Ley de Enjuiciamiento Criminal que en ese marcado respeto de las garantías procesales que debe mantenerse durante toda la infiltración, señala que cuando las actuaciones de investigación pudieran afectar a los derechos fundamentales, el agente encubierto deberá solicitar del órgano judicial competente las autorizaciones que, al respecto, establezca la Constitución y la Ley, así como cumplir las demás previsiones legales aplicables, previsión que es tan solo la aplicación ge-

21 De este parecer se muestran HERNAIZ, PHELAN y CAMACHO (2014:131177) al señalar que "cuando en una sociedad hay corrupción, las oportunidades no se ofrecen sobre la libertad de elegir (basadas en normas claras y transparentes), sino desde la discrecionalidad del funcionario o de la persona encargada de aportar el servicio o el bien. Esto se observa desde de lo micro hasta lo macro; desde obtener un pasaporte hasta adquirir un crédito para importar alimentos".

22 En este sentido ver ASENCIO MELLADO, J. M., (1989) y las Sentencias del Tribunal Supremo español de 22 de enero, de 4 y de 24 de abril de 2003, donde se afirma que todo lo que el agente haya podido conocer o descubrir, directa o indirectamente, en virtud de dicha actividad ilícita e ilegal, no podrá utilizarse en el proceso. 
neral del principio que exige autorización judicial para la adopción de cualquier medida restrictiva de derechos fundamentales, sin plantear ninguna especificidad especial el hecho de que esta solicitud la realice un agente encubierto ${ }^{23}$.

Igualmente se establece que la información que vaya obteniendo el agente encubierto deberá ser puesta a la mayor brevedad posible en conocimiento de quien autorizó la investigación, dejando también abierta la posibilidad legal, que criticamos, de que dicha autorización la haya llevado a cabo el Ministerio Fiscal. De nuevo aquí nos mostramos contrarios a la autorización de la figura del agente encubierto por parte del Ministerio Fiscal ya que, si es este el que autorizó la intervención del mismo, a él será a quien se deba comunicar la información obtenida, que escaparía, en este caso del control judicial al que estamos haciendo referencia mostrándonos más partidarios de que dicha información se dirija a quien tenga a su cargo la instrucción, es decir, a la autoridad judicial ${ }^{24}$.

Sobre los cauces a través de los cuales se cumpliría con este deber de información parece que resultaría mucho más operativo que el agente infiltrado no se comunique directamente con el órgano jurisdiccional por lo que de riesgo para su propia integridad podría conllevar, motivo por el cual abogamos por el cumplimiento de este deber a través de persona interpuesta siendo especialmente cuidadosos en la elección de esta persona cuando se trata de investigación de delitos de corrupción pues nunca se puede llegar a saber con absoluta certeza quien podría estar afectado por dicha trama de corrupción, pudiendo ponerse en peligro no solo el éxito de la operación, sino incluso también la propia vida del agente encubierto.

En relación con el destino que debe darse a este relato de hechos por parte del agente infiltrado, la regulación española señala que

23 En este sentido ver ORTELLS RAMOS, M. (1996).

24 En este sentido, GASCON INCHAUSTI, F., (2001) considera que el Fiscal no puede ser recipiendario válido de la información que aporte el agente encubierto, puesto que dicha información ha de dirigirse a quien tenga a su cargo la instrucción, puesto que puede servir como base para la apertura del juicio oral o el sobreseimiento, siendo absurdo que toda la información, en caso de que se remitiera al Fiscal, solo pudiera servir para que este pidiera a su vez, otras diligencias, siendo rebajada está medida de verdadera diligencia de investigación propia de la fase de instrucción a mera actividad de comprobación previa a la apertura de un sumario o de unas diligencias previas. 
deberá aportarse al proceso en su integridad, valorándose en conciencia por el órgano judicial competente, lo que garantiza que no solo se adjuntaran al proceso aquellos testimonios o hechos que sirvieran para conseguir la incriminación del imputado sino también aquellos que pudieran servir para fundamentar su inocencia.

\subsection{IDENTIDAD SUPUESTA Y PROTECCIÓN DEL AGENTE ENCUBIERTO}

Sobre la forma en que se va a conceder esa identidad ficticia o supuesta debemos señalar que la misma será otorgada por el Ministerio del Interior por el plazo de seis meses prorrogables por períodos de igual duración, quedando los agentes legítimamente habilitados para actuar en todo lo relacionado con la investigación concreta y a participar en el tráfico jurídico y social bajo tal identidad.

La resolución por la que se acuerde deberá consignar el nombre verdadero del agente y la identidad supuesta con la que actuará en el caso concreto, debiendo ser dicha resolución reservada, manteniéndose fuera de las actuaciones con la debida seguridad, concepto criticable por lo indeterminado que resulta y motivo por el cual hubiéramos considerado mucho más acertado que se estableciera para la misma la necesidad de decretar el secreto de sumario del artículo 302 de la Ley de Enjuiciamiento Criminal ${ }^{25}$.

Precisamente sobre esta identidad supuesta y, más concretamente, sobre la posibilidad de mantener dicha identidad cuando el agente encubierto testifique en el proceso que pudiera derivarse de los hechos en que hubiera intervenido, es sobre la que planea una de las mayores interrogantes sobre los riesgos que la actuación de los agentes encubiertos pueden conllevar para las garantías procesales de un Estado de Derecho, ya que desde el punto de vista procesal, la actividad de un agente encubierto podría llegar a afectar gravemente a distintos derechos fundamentales de las personas investigadas, no solo por la intromisión continuada en la vida privada de estas, atentando, como vimos, contra su derecho a la intimidad, sino también contra su derecho de

25 Sobre estos aspectos ver TOME GARCIA, J. A., (1999) y MORAL GARCIA, A., (2000). 
defensa, tanto durante la instrucción como durante la fase de juicio oral, encontrándonos en este momento con una doble posible interpretación de que es lo que debe mantenerse oculta durante la fase de juicio oral para poder salvaguardar ese derecho de defensa: la identidad real del agente encubierto o la misma existencia de una infiltración policial.

De una lectura atenta de la normativa que estamos analizando parece deducirse que la identidad real del agente encubierto deberá quedar oculta hasta, al menos, la finalización del proceso, siendo denominado en todo momento por la identidad supuesta que le hubiera sido otorgada, exigiéndose la existencia de una resolución motivada en la que se acuerde dicho extremo y siéndole de aplicación, como no podía ser de otra manera, la legislación referente a la protección de testigos que se encuentra recogida en la Ley Orgánica 19/1994, de 23 de diciembre, de protección a testigos y peritos en causas criminales, todo ello con el objetivo, no ya solo de asegurar el éxito de la investigación, sino de proteger personalmente al agente encubierto, a las personas de su familia y de su entorno ${ }^{26}$.

En el sentido de colaborar en garantizar la seguridad de los agentes que actúen de manera encubierta o con identidad falsa, resultan interesantes, por afectar a todos los Estados miembros, las Resoluciones del Consejo de la Unión Europea de fechas de 23 de noviembre de 1995, relativas a la protección de testigos en el marco de la lucha contra la criminalidad organizada internacional ${ }^{27}$, y de 20 de diciembre de 1996,

26 Ley Orgánica 19/1994, de 23 de diciembre, de protección a testigos y peritos en causas criminales, $B O E$ de 24 de diciembre de 1994, cuyo contenido responde al propósito protector, admitido por el Tribunal Europeo de Derechos Humanos, y cuyo principio general se hacía patente en la Resolución 827/1993, de 25 de mayo, del Consejo de Seguridad de Naciones Unidas, concerniente a la antigua Yugoslavia. Esta regulación es considerada por REUS MARTINEZ, N., (2002) como manifiestamente insuficiente, opinión que comparte en los mismos términos GARZÓN REAL, B., (2000).

27 Resolución del Consejo, de 23 de noviembre de 1995, relativa a la protección de los testigos en el marco de la lucha contra la criminalidad organizada internacional, DOCE C 327 de 7.12.1995, que se encarga de exigir a los Estados miembros la protección eficaz de la seguridad de tales testigos entendiendo por testigo a toda persona, cualquiera que sea su situación jurídica, que posea informaciones consideradas por la autoridad competente como importantes en un proceso penal, y susceptibles de poner a la persona en peligro si éstas 
relativa a las personas que colaboran con el proceso judicial en la lucha contra la delincuencia internacional organizada ${ }^{28}$.

Sin embargo, este hecho no puede conllevar que se oculte la propia existencia de la labor del agente encubierto, ya que no resulta admisible en un Estado de Derecho que pueda mantenerse en secreto para el encausado la circunstancia de que ha sido objeto de una investigación encubierta, puesto que ello atentaría contra las más elementales bases del derecho de defensa y del principio de contradicción, ya que tan solo conociendo el origen y la forma de acceso a las fuentes de prueba podrá el sujeto pasivo del proceso penal defenderse frente a su posible ilicitud y someterlas a plena contradicción ${ }^{29}$.

son divulgadas, contra cualquier forma de amenaza, presión o intimidación directa o indirecta, antes, durante y después del proceso, protección que habrá de garantizarse también a los familiares del testigo, potenciándose la posibilidad de que los programas de protección de testigos puedan ser aplicados más allá de las fronteras de cada Estado.

Resolución 97/C 10/01 del Consejo, de 20 de diciembre de 1996, relativa a las personas que colaboran con el proceso judicial en la lucha contra la delincuencia internacional organizada, DOCE C 10 de 11.01.97, se refiere al fomento de la colaboración con el proceso judicial, entendiéndose por tal, conforme a lo dispuesto en el articulado de dicha Resolución, al hecho de facilitar información útil a las autoridades competentes para fines de investigación y obtención de pruebas acerca de la composición, estructura o actividades de las organizaciones delictivas, sus vinculaciones, incluidas las internacionales, con otros grupos delictivos y los delitos cometidos o que pudiesen cometer dichos grupos, brindando una ayuda eficaz y práctica que contribuya a luchar contra los mismos, mediante el ofrecimiento de beneficios específicos por parte de las autoridades de los Estados miembros, de las personas que participen o hayan participado en cualquier tipo de organización delictiva, y que rompan su vinculación con la misma, esforzándose en evitar la continuación de las actividades delictivas y ayudando a las autoridades en su investigación para la reconstrucción de los hechos o la identificación y detención de los autores.

De esta opinión se muestra la práctica totalidad de la Doctrina, llegando a afirmar GASCÓN INCHAUSTI, F., (2001) que lo ideal sería que, a efectos prácticos, la resolución por la que se acordara la infiltración solo expresara la identidad de cobertura del agente encubierto, consignándose la expresión de su identidad real en un anexo que se guardaría fuera de las actuaciones con la debida seguridad, teniendo un carácter secreto ex lege y de duración indefinida, opinión que compartimos en contra de la de MORENO CATENA, V., (1999) que estima procedente la existencia igualmente de dos resoluciones, la primera que tan solo autorizara la infiltración policial y la segunda 


\subsection{RESPONSABILIDAD DEL AGENTE ENCUBIERTO}

Por último señalar que el apartado 5 del artículo 282 bis de la Ley de Enjuiciamiento Criminal regula el régimen de responsabilidad penal, o mejor dicho de exención de responsabilidad penal, al que están sometidos aquellos sujetos que actúen como agentes infiltrados y en este sentido se establece que el agente infiltrado estará exento de responsabilidad criminal por aquellas actuaciones que sean consecuencia necesaria del desarrollo de la investigación, siempre que guarden la debida proporcionalidad con la finalidad de la misma y no constituyan una provocación al delito, figura que se encuentra prohibida en nuestro ordenamiento jurídico.

Del mismo modo, también se señala el cauce para poder proceder penalmente contra un agente encubierto, estableciéndose que el Juez competente para conocer la causa deberá, tan pronto tenga conocimiento de la actuación de algún agente encubierto en la misma, requerir informe relativo a tal circunstancia de quien hubiere autorizado la identidad supuesta, configurándose la petición de este informe como un auténtico requisito de procedibilidad, sin el cual no podría continuarse ningún proceso penal contra un agente encubierto debidamente autorizado para operar como tal, ya que sobre la base del mismo el Juez competente podrá decidir, según su criterio, el archivo de la causa por concurrir los requisitos de exención exigidos o, por el contrario, en caso de que estos no concurran, ordenar la continuación del procedimiento.

\section{INFILTRACIÓN POLICIAL Y RECUPERACIÓN DE ACTIVOS}

En España, en los últimos tiempos, el Estado se ha impuesto la necesidad de dirigir sus esfuerzos no sólo a la investigación de los delitos de corrupción, en orden a poder imponer una determinada pena a los responsables de los mismos, una vez declarada su participación en los hechos

que recogiera ambas identidades, la supuesta y la oculta, siendo esta última la que tendría carácter reservado, pues consideramos que el imputado tendría derecho no solo a saber que ha existido una infiltración policial, sino también a saber quien ha sido la persona que ha actuado como agente encubierto. 
delictivos, labor en la que juega un importante papel la infiltración, sino también a lograr la recuperación de los activos procedentes del delito.

Esto es así porque tan importante es para los ciudadanos, el cumplimiento certero de la pena como la recuperación de esos activos que hagan que no compense el delinquir, es decir, que no merezca la pena pasar, en el peor de los casos unos años privado de libertad, sabiendo que a la salida te espera el disfrute de esos activos, ya sean bienes o dinero, que no llego a ser recuperado.

Así, uno de los principales instrumentos adoptados para conseguir ese propósito, ha sido la puesta en marcha de la denominada Oficina para la Recuperación y Gestión de Activos que, mediante su regulación en la Ley de Enjuiciamiento Criminal, se configura como un órgano al que corresponden las competencias de localización, recuperación, conservación, administración y realización de los efectos, bienes, instrumentos y ganancias procedentes de actividades delictivas cometidas en el marco de una organización criminal y de cualesquiera otras que se le atribuyan en la ley ${ }^{30}$.

Aunque durante cinco años esa previsión no llegó a ser desarrollada reglamentariamente lo cierto es que el Centro de Inteligencia contra el Terrorismo y el Crimen Organizado, dependiente de la Secretaría de Estado de Seguridad del Ministerio del Interior, con el apoyo operativo de las Fuerzas y Cuerpos de Seguridad del Estado, vino desempeñando funciones de localización de activos procedentes de delitos, lo que nos da una idea de la importancia de la actuación policial en el éxito de la nueva Oficina, actuación policial que, en ocasiones, se desarrollaba a través de la infiltración de agentes encubiertos en el seno

30 Si bien la redacción de dicho artículo procede de la reforma operada por la Ley Orgánica 1/2015, de 30 de marzo, por la que se modifica la Ley Orgánica 10/1995, de 23 de noviembre, del Código Penal, lo cierto es que dicha institución se introdujo mucho antes, concretamente cinco años antes, a través de la Ley Orgánica 5/2010, de 22 de junio, también de modificación del Código Penal, que en su disposición final primera ya contemplaba la creación de una Oficina de Recuperación de Activos, a la que la nueva regulación atribuye, no solo la función de localizar y recuperar los bienes, sino también la función de administrarlos y gestionarlos, motivo por el cual se modifica su nombre pasando a llamarse Oficina para la Recuperación y Gestión de Activos. 
de las organizaciones criminales para llevar a cabo entre otras, funciones de investigación patrimonial ${ }^{31}$.

No obstante, y pese a la excelente labor realizada por las Fuerzas y Cuerpos de Seguridad, al no existir órganos especializados en su gestión, una vez decomisados, esos activos quedaban a disposición de los órganos jurisdiccionales que, por lo general, ordenaban su realización mediante los sistemas tradicionales de venta por persona especializada o subasta pública, mecanismos cuya ineficacia en los procedimientos de mayor complejidad condujo a reafirmar la necesidad de poner en funcionamiento un órgano que no solo sirviera para localizar y recuperar los bienes si no que además los administrara y los gestionara.

En este contexto nace la Oficina de Recuperación y Gestión de Activos, quedando afectados esos bienes, entre otros fines: al abono de las indemnizaciones de las víctimas, a la realización de proyectos sociales o al impulso de la cooperación internacional en la lucha contra las formas graves de criminalidad, haciendo de la creación de esta oficina, una relevante medida de regeneración democrática y justicia social ${ }^{32}$.

Para incrementar la eficacia en la lucha frente al crimen organizado, con la finalidad de privar a las organizaciones criminales del producto obtenido de sus actividades delictivas, se han establecido una serie de pautas que permitan, por ejemplo, la posible adjudicación provisional de los bienes embargados, a las Fuerzas y Cuerpos de Seguridad del Estado, o la gestión de aquellos bienes custodiados por el Ministerio del Interior y que, por su naturaleza, sufran una importante depreciación, como es el caso de los vehículos incautados y embargados ${ }^{33}$.

31 En este sentido compartimos la opinión ya apuntada por RODRÍGUEZ GARCÍA (2008).

32 Los fines, estructura y funcionamiento de la ORGA los encontramos regulados en el Real Decreto 948/2015, de 23 de octubre, por el que se regula la Oficina de Recuperación y Gestión de Activos. Boletín Oficial del Estado núm. 255 de 24 de octubre de 2015.

33 Acuerdo de colaboración a efecto de regular la interrelación del personal del Ministerio del Interior con la Oficina de Recuperación y Gestión de Activos y de coordinación y apoyo para el desarrollo de sus funciones, de 20 de junio de 2016, firmado entre la Secretaría de Estado de Seguridad y la Secretaría de Estado de Justicia. Disponible en https://ssweb.seap.minhap.es/docconvenios/rest/descargaFicheros/19461 


\section{Consideraciones finales}

Llegado este momento corresponde realizar unas breves reflexiones sobre los aspectos que hemos tratado en nuestro trabajo, y así, en primer lugar, debemos concluir que la infiltración policial pese a tratarse de una figura muy controvertida y en muchos casos cuestionada, se ha revelado como necesaria para luchar eficazmente contra la corrupción y el crimen organizado no solo desde el punto de vista interno sino también en el plano internacional, lo que se deduce de su inclusión en numerosos instrumentos normativos tales como el Convenio de Asistencia Judicial en materia penal entre los Estados miembros de la Unión Europea de 2000 como la recientemente aprobada Directiva 2014/41/CE del Parlamento Europeo y del Consejo, de 3 de abril de 2014, relativa a la orden europea de investigación en materia penal.

En segundo lugar, debemos señalar que, pese a ello, debemos ser muy cuidadosos a la hora de recurrir a esta figura exigiendo el pleno respeto de las garantías procesales y siendo como hemos criticado, totalmente inaceptable que el Ministerio Fiscal pueda autorizar una infiltración policial, ya que, en nuestra opinión, tan solo la autorización judicial garantiza las exigencias de excepcionalidad, proporcionalidad y necesidad que deben exigirse para la adopción de una medida tan restrictiva de derechos fundamentales como la que nos ocupa.

Debemos, en tercer lugar, alabar la precisión con la que se delimita el ámbito de aplicación de esta figura en la regulación española, limitándose tan solo a aquellos casos de delincuencia organizada y para una serie determinada de delitos, así como por los evidentes esfuerzos por garantizar la seguridad de los agentes, si bien reclamaríamos un mayor rigor en la forma en que se debe tratar la concesión de la identidad supuesta, pronunciándonos de forma decidida a favor de la adopción del secreto de sumario para dichas actuaciones así como por una mejora del régimen de responsabilidad al que están sometidos los agentes encubiertos en orden a dotar su actuación de una mayor seguridad jurídica.

En cuarto lugar, debemos felicitarnos por el hecho de que esté prohibida la figura del agente provocador o de la provocación al delito, tan cercanas en ocasiones a la del agente infiltrado, pues compartimos la idea de que esta situación no es admisible en un Estado de Derecho, que no puede 
recurrir a convertirse él mismo en un delincuente para conseguir atrapar a otros delincuentes, opinión que basamos no solo en los diferentes pronunciamientos jurisprudenciales que hemos recogido en nuestro trabajo sino también en las opiniones doctrinales que, de la misma forma, compartimos.

Del mismo modo, y en quinto y último lugar, consideramos muy adecuada la creación de la Oficina de Recuperación y Gestión de Activos en la lucha contra la corrupción y el crimen organizado por cuanto permite, por un lado, optimizar la gestión de los recursos incautados procedentes de la actividad ilícita mientras que, por otro, reconcilia a la sociedad con la idea de que se está luchando eficazmente contra la corrupción, siendo destinataria además de parte de lo obtenido de la realización de dichos bienes.

Por todas estos motivos, valoramos de forma positiva, aunque con las cautelas expresadas en nuestro trabajo, la regulación de la figura del agente encubierto en nuestro derecho interno, teniendo siempre en consideración el respeto al principio de proporcionalidad y al resto de garantías procesales exigibles ya que en nuestra opinión, la eficacia y la eficiencia de una medida jamás debería ser alcanzada con el sacrificio de los derechos, libertades y garantías de los ciudadanos, ya que este es un precio demasiado alto que el Estado de Derecho no puede permitirse pagar.

\section{Bibliografía}

ALONSO PÉREZ, F., (2002) "La figura del agente encubierto", Revista de Documentación del Ministerio del Interior, núm. 9, octubre-diciembre 2002.

ASENCIO MELLADO, J. M., (1989) Prueba prohibida y prueba preconstituida, Madrid.

BACHMAIER WINTER, L., (2012) "La propuesta de Directiva europea sobre la orden de investigación penal: valoración crítica de los motivos de denegación", Diario La Ley, núm. 7992.

BUENO DE MATA, F. (2012), "El agente encubierto en Internet: mentiras virtuales para alcanzar la justicia”, en PEREZ-CRUZ MARTÍN, A.J. y FERREIRO BAAMONDE, X. (Dirs.), Los retos del Poder Judicial ante la sociedad globalizada, Universidad de A Coruña

CARDOSO PEREIRA, F., (2016), El Agente Infiltrado desde el Punto de Vista del Garantismo Procesal Penal - Edición Revisada y Actualizada con la Ley Orgánica 13/2015 y la Ley 41/2015, de 5 de Octubre. Editorial Juruá Internacional. 
CARMONA SALGADO, C., (2003) La circulación y entrega vigilada de drogas y el agente encubierto en el marco de la criminalidad organizada sobre narcotráfico, en Estudios jurídico-penales y políticos-criminales sobre tráfico de drogas y figuras afines (Lorenzo Morillas Cueva, coordinador), Dykinson, Madrid.

COSTA ANDRADE, M., (1992) Sobre as proibições de prova em proceso penal, Coimbra Editora, Coimbra, 1992.

DARIO CERINA, G., (2008) "La lucha contra la delincuencia organizada: Notas desde el Derecho Penal sustantivo y referencias al agente encubierto como medio de investigación extraordinario en una perspectiva interna y supranacional", en Dos Décadas de Reformas Penales (coord.: SANZ MULAS, N.), Ed. Comares, Granada.

DELGADO GARCÍA, M. D., (1996) “El agente encubierto: técnicas de investigación. Problemática y legislación comparada”, en La criminalidad organizada ante la Justicia (GUTIERREZ-ALVIZ CONRADI, F., coord.), Universidad de Sevilla, Sevilla.

DELGADO MARTÍN, J., (2000) "El proceso penal ante la criminalidad organizada. El agente encubierto”, Actualidad Penal, núm. 2.

DELGADO MARTÍN, J., (2001) "El proceso penal ante la criminalidad organizada. El agente encubierto”, en Problemas actuales de la Justicia Penal, (Pico i Junoy, Director), José $\mathrm{M}^{\mathrm{a}}$ Bosch Editor.

DIAZ PITA, M. P., (2015) "La orden europea de investigación en materia penal (OEI) y la lucha contra la criminalidad organizada transnacional en la Unión Europea", Observatorio de Criminalidad Organizada Transnacional, Mayo de 2015, disponible en http://crimtrans.usal.es/?q=node/138.

DUEÑAS JIMÉNEZ, V., (2000) “Instrumentos y mecanismos de cooperación judicial”, El espacio europeo de libertad, seguridad y justicia, Secretaría General Técnica, Ministerio del Interior, Madrid.

GARZÓN REAL, B., (2000) “Cooperación jurídica internacional en el ámbito del blanqueo de dinero y espacio de Seguridad, Libertad y Justicia en la Unión Europea”, en Prevención y represión del blanqueo de capitales, Estudios de Derecho Judicial, 28-2000, Consejo General del Poder Judicial, Madrid.

GASCÓN INCHAUSTI, F., (2001) Infiltración policial y agente encubierto, Comares, Granada.

GOMEZ DE LIAÑO FONSECA-HERRERO, M., (2004) Criminalidad organizada y medios extraordinarios de investigación, Colex, Madrid.

GUARIGLIA, F., (1994) "El agente encubierto ¿un nuevo protagonista en el procedimiento penal?”, en Jueces para la Democracia, núm. 23.

GUEDES VALENTE, M. M., (2008) "La investigación del crimen organizado, entrada y registro en domicilios por la noche, el agente infiltrado y las intervenciones de las comunicaciones" en Dos décadas de reformas penales 
(coord.: SANZ MULAS, N.), Editorial Comares, Granada (traducido del original portugués por CARRIZO GONZÁLEZ-CASTELL, A.).

IRURZUN MONTORO, F., (2002) "Últimos avances y propuestas de la Unión Europea en la cooperación judicial penal”, en Revista del Ministerio Fiscal, núm. 10. LAFONT NICUESA, L. (2015) "El agente encubierto en el proyecto de reforma de la Ley de Enjuiciamiento Criminal” Diario La Ley, número 8580.

LOPEZ ORTEGA, J. J., (1996) "La intimidad como bien jurídico, Estudios sobre el Código Penal de 1995 (parte especial)”, Cuadernos de Derecho Judicial, Consejo General del Poder Judicial.

MARTIN GARCÍA, A. L. y BUJOSA VADELL, L.M., (2016) La obtención de prueba en materia penal en la Unión Europea, Editorial Atelier, Barcelona.

MARTINEZ GARCÍA, E., (2016) La orden europea de investigación, Editorial Tirant lo Blanch, Valencia.

MORAL GARCIA, A., (2002) "El secreto de las actuaciones en el proceso penal”, Jornadas sobre garantías del imputado en el proceso penal, Estudios Jurídicos: Ministerio Fiscal., núm. I.

MORENILLA RODRÍGUEZ, J. M., (1993) "El derecho al respeto de la esfera privada en la jurisprudencia del Tribunal Europeo de Derechos Humanos", La Jurisprudencia del Tribunal Europeo de Derechos Humanos, Cuadernos de Derecho Judicial, Consejo General del Poder Judicial.

MORENO CATENA, V., (1999) “Los agentes encubiertos en España”, Otrosí del Ilustre Colegio de Abogados de Madrid, núm. 10.

ORTELLS RAMOS, M., (1996) "Exclusividad para la restricción de los derechos fundamentales y ámbitos vedados a la injerencia jurisdiccional”, en Medidas restrictivas de derechos fundamentales, Cuadernos de Derecho Judicial, Consejo General del Poder Judicial, Madrid.

REUS MARTINEZ, N., (2002) “La Justicia Penal y la Unión Europea. Convenios existentes. Especial consideración del Espacio Schengen”, Revista Jurídica de la Comunidad de Madrid, número 12, enero-abril de 2002.

RIFÁ SOLER, J. M., (1999) “El agente encubierto o infiltrado en la nueva regulación de la Ley de Enjuiciamiento Criminal”, en Poder Judicial, núm. 55, 1999, pp. 157188, en La Ley Penal: Revista de derecho penal, procesal y penitenciario.

RIFÁ SOLER, J. M., (2001) “La figura del infiltrado como sujeto de protección”, en La protección de testigos y peritos en causas criminales. Jornadas Internacionales de Derecho Procesal, Ponencias y comunicaciones, CEDMA, Málaga.

RODRÍGUEZ GARCÍA, N. (2008), “Asistencia judicial penal para luchar contra la corrupción, el blanqueo de capitales y la delincuencia organizada: algunos apuntes sobre el Convenio Europeo de 2000", Corrupción y delincuencia económica, Ediciones Gustavo Ibáñez, Bogotá. 
SEQUEROS SAZATORNIL, F., (2000) El tráfico de drogas ante el ordenamiento jurídico (evolución normativa, doctrinal y jurisprudencial, La Ley, Madrid.

TOME GARCIA, J. A., (1999) "Imputación, derecho de defensa y secreto del sumario", Revista de Derecho Procesal, núm. 1.

VALIÑO CES, A. (2016) “Una lectura crítica en relación con el agente encubierto informático tras la Ley Orgánica 13/2015”, Diario La Ley, núm. 8731. Sección Tribuna, 30 de marzo de 2016. Ref. D-132.

VV.AA., (2015) Reconocimiento mutuo de resoluciones penales en la Unión Europea, (ARANGÜENA FANEGO, C., DE HOYOS SANCHO, M., RODRÍGUEZ-MEDEL NIETO, C., coordinadoras), Editorial THOMSON REUTERS-ARANZADI, Cizur Menor.

VV.AA. (2016) Conclusiones de las Jornadas sobre el Marco Jurídico de Actuación del Agente Encubierto : Madrid, 29 de mayo de 2015 (CONDE-PUMPIDO GARCÍA, P., DELGADO MARTÍN, J., GÓMEZ RODRÍGUEZ, C. y ROLDÁN LÓPEZ, E.,) Editorial: CONSEJO GENERAL DEL PODER JUDICIAL.

\section{DADOS DO PROCESSO EDITORIAL}

(http://www.ibraspp.com.br/revista/index.php/RBDPP/about/editorialPolicies)

- Recebido em: 20/03/2017

- Controle preliminar e verificação de plágio: 23/03/2017

- Avaliação 1: 25/03/2017

- Avaliação 2: 30/03/2017

- Avaliação 3:05/04/2017

Equipe editorial envolvida

- Editor-chefe: 1 (VGV)

- Editor-associado: 1 (MMGV)

- Revisores: 3

- Decisão editorial preliminar: 06/04/2017

- Retorno rodada de correções 1: 13/04/2017

- Decisão editorial preliminar 2: 15/04/2017

- Retorno rodada de correções 2: 19/04/2017

- Decisão editorial final: 23/04/2017

\section{COMO CITAR ESTE ARTIGO:}

CARRIZO GONZÁLEZ-CASTELL, Adán. La infiltración policial en España como medio de investigación en la lucha contra la corrupción. Revista Brasileira de Direito Processual Penal, Porto Alegre, vol. 3, n. 2, p. 511-536, mai./ago. 2017. https://doi.org/10.22197/rbdpp.v3i2.64

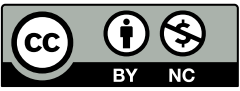

Esta obra está licenciada com uma Licença Creative Commons Atribuição-NãoComercial 4.0 Internacional. 